\title{
Effects of Partial Tillage Seeding of Hairy vetch on Green Manure Biomass and Rice Yield in Rice-based Cropping System
}

\author{
Jin-Hee Ryu, Weon-Tai Jeon*, Min-Tae Kim, Jong-Seo Choi, Sook-Jin Kim, \\ Kwang-Seop Kim, Ki-Do Park, and Hang-Won Kang \\ National Institute of Crop Science, RDA, Suwon 441-857, Republic of Korea
}

(Received: October 7 2013, Accepted: December 2 2013)

To investigate the effect of partial tillage seeding of hairy vetch on green manure biomass and rice yield, on-farm experiment was conducted at eco-friendly hairy vetch cultivation area located in Yesan-gun, Chungcheongnam-do. Seeding methods of hairy vetch consisted of partial tillage seeding (PTS) and broadcasting before rice harvesting (BBRH). Hairy vetch was incorporated into soil on May 18 and rice seedling was transplanted on May 26. The growths of hairy vetch before overwintering were investigated on November 11. Plant height of BBRH plot was longer than that of PTS plot, but somewhat larger number of seedling stand was found in PTS. Biomass and N production of hairy vetch were investigated on May 18. Results of the investigation showed no difference between two seeding methods. Although the seeding time was 21 days late in PTS, the biomass of hairy vetch and rice yield were equivalent to those of BBRH seeding, so we conclude that PTS could improve overwintering survival of hairy vetch in rice cropping system.

Key words: Hairy-vetch, Partial tillage seeding (PTS), Broadcasting before rice harvesting (BBRH), Green manure

Effects of incorporation of hairy vetch on rice yield and its components in response to different seeding methods.

\begin{tabular}{ccccccc}
\hline \hline Seeding method & Cultivar & Panicle & Spikelets & Ripened grain & 1,000 grain weight & Rice yield \\
\hline \multirow{2}{*}{ PTS $^{\dagger}$} & $\begin{array}{c}\text { Cheongpung } \\
\text { bora }\end{array}$ & 23.7 & 75.1 & 83.9 & Brown rice, g & $\mathrm{kg}^{-1} \mathrm{a}^{-1}$ \\
\cline { 2 - 7 } & Imported cultivar & 24.2 & 68.6 & 79.0 & 21.0 & $467 \mathrm{a}$ \\
\hline $\mathrm{PTS}^{\dagger}$ & no. panicle & & 21.1 & $456 \mathrm{a}$ \\
\hline $\mathrm{BBRH}^{\ddagger}$ & Cheongpungbora & 24.7 & 78.0 & 84.2 & 21.5 & $467 \mathrm{a}$ \\
\hline $\mathrm{BBRH}^{\ddagger}$ & Imported cultivar & 23.3 & 74.5 & 86.0 & 21.5 & $455 \mathrm{a}$ \\
\hline
\end{tabular}

'PTS: partial tillage seeding, ${ }^{\ddagger} \mathrm{BBRH}$ : broadcasting before rice harvesting 


\section{Introduction}

2000년대 이후 다수성 위주에서 친환경 안전 농산물 생 산으로 패러다임이 변화하면서 녹비작물을 이용한 친환경 벼 재배 및 안전 농산물 생산 연구의 중요성이 부각되었다. 녹비작물은 비료성분이 풍부하여 유기질비료로 사용되는 작 물로 이들은 화학비료 대체, 토양 물리성·화학성·생물상 개 선 및 경관 보전 효과 등 다양한 효과를 가지고 있다 (Azam, 1990; Hartwig and Ammon, 2002; Clark, 2007; Jeon et al., 2008; Jeon et al., 2011a). 녹비작물은 1930년대에 약 150,000 ha 이상이 재배되었으나 화학비료의 비료자급률이 $100 \%$ 에 이르는 1970 년대 초반부터 재배가 거의 보고되지 않았다 (Lee, 1983). 이 후 친환경 농산물에 대한 국민적 관 심 증가와 정부의 녹비작물 종자대 지원사업 등으로 녹비작 물 재배가 증가하여 2010년 144,000 ha까지 재배면적이 증 가 (FACT, 2011) 하였다. 그러나 그 후 자운영의 알팔파 물 바구미 발생 증가, 녹비작물 재배 시 월동 안전성 확보의 어 려움 등으로 2012년에는 녹비작물 재배면적이 98,098 ha로 다소 감소하였다. 녹비작물 중 두과 녹비작물인 헤어리베치 (Vicia villosa)는 화학비료 대체 효과가 뛰어나 벼 등 다수 작물에 대한 녹비 이용 기술이 개발되었고, 2012년도에는 $42,700 \mathrm{ha}$ 가 재배되어 전체 녹비작물 재배면적의 $43.5 \%$ 를 차지하였다 (MAF, 2012). 그러나 최근 기상이변에 따른 파 종기 호우 및 월동 중 최저기온 변동 등으로 동계 월동의 어 려움이 커지고 있다. 따라서 친환경농업 보급에서 매우 중 요한 녹비작물 헤어리베치의 확대 보급을 위해서는 월동 안 전성 및 적정 생체량를 확보할 수 있는 헤어리베치의 안정 적 재배기술 개발이 시급하다. 현재 우리나라에 재배되고 있는 헤어리베치는 벼 입모 중 파종이 대부분을 차지하고 있다. 벼 입모 중 파종은 생력적인 재배방법이기는 하지만 입모가 불균일하고, 습해 및 한해에 취약하다 (Kim et al., 2002). 따라서 녹비작물의 재배 안전성을 높이고 최근 이상 기상 등 기후변화에 대응하기 위한 파종방법의 개발이 필요 하다. 본 연구는 답리작 헤어리베치의 재배 안정성 제고를 위해 헤어리베치의 부분경운 파종방법에 대한 농가 실증 시
험을 통하여 현장에서 헤어리베치 부분경운 파종방법이 녹 비 생체량, 질소생산성과 후작 벼의 생육 및 수량에 미치는 영향에 대한 기초 자료를 얻고자 수행하였다.

\section{Materials and Methods}

본 시험은 2011년 9월부터 2012년 10월까지 충남 예산군 고덕면 소재 농가포장 (만경통)에서 수행하였다. 시험에 사 용된 헤어리베치의 종자는 국립식량과학원에 육성한 청풍 보라와 수입종 (중국산)을 사용하였다. 파종방법은 벼 입모 중파종과 부분경운파종의 2 가지 방법으로 실시하였는데, 벼 입모중파종은 2011년 9월 28일에 파종하였고 부분경운 파종은 벼 수확후 10 월 19 일에 파종하였다. 처리별 헤어리 베치 파종량은 $10 \mathrm{a}$ 당 $6 \mathrm{~kg}$ 으로 하였다. 입모 중 파종은 벼 를 수확하기 전에 손으로 파종하였고, 부분경운 파종은 볏 짚을 제거한 후 트랙터 부착 파종기 (Jeon et al., 2008)를 이용하였다.

녹비작물 조사 및 분석 녹비작물 생체량 조사는 2012 년 5 월 18 에 $1 \mathrm{~m}^{2}(1 \mathrm{~m} \times 1 \mathrm{~m})$ 의 면적을 기준으로 하여 녹비 작물을 채취하여 생체중을 측정하고 비닐하우스에서 충분 히 풍건 후 $60^{\circ} \mathrm{C}$ 에서 24 시간 건조시켜 건물중을 측정하였 다. 녹비작물의 투입은 2012년 5월 18일에 로타리 경운으로 환원하였다. 식물체의 질소와 탄소는 CNS2000 (Leco, USA) 을 이용하여 분석하였고 그 외의 토양 및 식물체 분석은 농 촌진흥청 (NIAST, 2000) 방법에 준하였다.

벼 재배 및 생육, 수량조사 벼 품종은 농가 재배품종 인 중만생종 삼광벼를 이용하였고, 벼 재배는 헤어리베치를 토양에 환원한 후 무비로 재배하였다. 벼 재배 중 생육과 수 량 및 수량구성요소 조사는 농업과학기술 연구조사분석기 준 $(\mathrm{RDA}, 2003)$ 에 준하여 실시하였다. 벼 재배 중 생육조사 는 분얼기 (이앙 후 28일)와 출수기 (이앙 후 83일)에 초장 과 경수를 조사하였다.

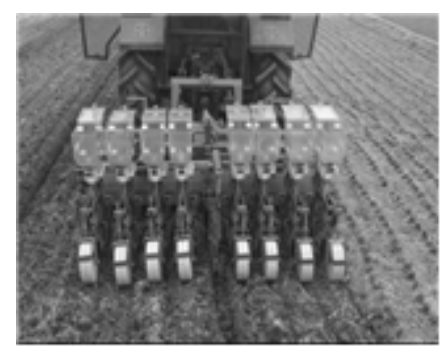

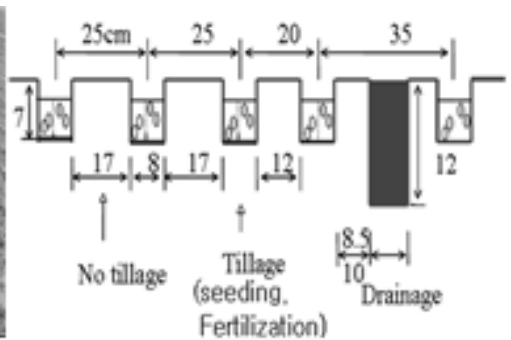

PTS $^{\dagger}$

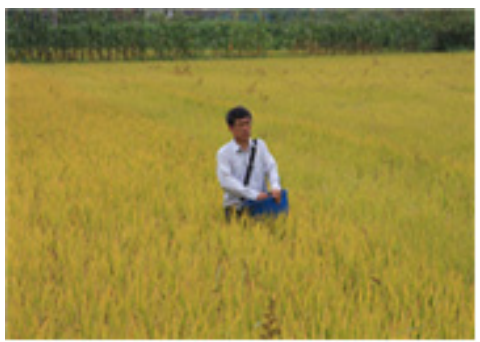

BBRH $^{\ddagger}$

${ }^{\dagger}$ PTS : partial tillage seeding, ${ }^{\ddagger} \mathrm{BBRH}$ : broadcasting before rice harvesting

Fig. 1. Seeding methods of hairy vetch for rice cultivation. 
토양 분석 시험 전 토양분석을 위하여 녹비작물 재배 전에 0 10 $\mathrm{cm}$ 깊이와 $10 \sim 20 \mathrm{~cm}$ 깊이에서 토양시료를 3 반 복으로 채취하였다. 채취한 시료는 음건하여 $2 \mathrm{~mm}$ 체를 통 과된 것을 화학성 분석에 사용하였다. 토양화학성 분석은 농업과학기술원 토양 및 식물체 분석법 (NIAST, 2000)을 적용하여 $\mathrm{pH}$ 는 토양과 증류수의 비율을 $1: 5$ 로 하여 초자전 극법 (720P, iSTEK, USA)으로 측정하였고, 유기물은 원소 분석기 CNS2000 (LECO, USA)를 이용하여 탄소를 분석하 여 탄소함량에 계수 1.724 를 곱하여 산출하였고 질소분석에 도 CNS2000을 이용하였다. 유효인산은 Lancaster 법, 양이 온은 ICP (GBCSDS-270, Australia)를 사용하여 분석하였 다. 벼 재배기간 중인 분얼기와 출수기에 토양 암모니아태 질소를 분석하였는데, 분석은 Inject flower meter인 FIAstar 5000 (FOSS Sweden)을 이용하였다.

통계분석 방법 통계분석은 SAS 9.2. 버전을 이용하였 다. 벼 수량 및 수량구성요소 등은 5\% 유의수준에서 Duncan's multiple range test를 수행하였다.

\section{Results and Discussion}

헤어리베치의 파종 후 초기 생육 특성을 Table 1 에 나타 내었다. 9월 28일에 파종한 벼 입모중 파종이 10월 19일에 파종한 부분경운 파종보다 초장은 길었으나 입모수는 대체 로 적은 경향이었고 국립식량과학원에서 개발한 청풍보라 와 수입종과의 차이는 생육초기에 나타나지 않았다. 청풍보 라가 초장이 짧은 것은 파종이 약 21 일 늦은데 원인이 있는 것으로 생각되었고 입모수가 많은 것은 벼입모중파종은 산
파이고 볏짚으로 피복된 것에 비하여 부분경운 파종은 조파 (줄뿌림)으로 토중에 파종되어 입모율이 높은데 기인된 것 으로 사료 되었다. 이는 Jeon et al. (2011b)의 결과와 유사 하여 월동에 유리할 것으로 판단되었다.

헤어리베치의 토양 환원시기에 헤어리베치의 생체량와 질소생산량을 Table 2에 나타내었다.

헤어리베치의 생체량는 부분경운 파종이 벼 입모중 파종 보다 21일 늦었으나 생체량와 질소 생산성에서 파종방법 간 유의적 차이를 나타내지 않고 대등하였다. 부분경운 파종이 벼 입모중 파종보다 파종시기가 늦었음에도 대등한 생체량 를 생산한 것은 Jeon et al. (2011b) 등이 보고한 바와 같이 부분경운 파종 시 헤어리베치 종자가 토양 속에 파종되어 동해를 적게 받고 파종과정에서 배수로가 확보되어 습해가 경감되어 헤어리베치 생육에 더 유리했기 높았기 때문으로 생각된다. 또한 벼 조생종 재배지에 헤어리베치 부분경운 파종방법을 적용하여 헤어리베치 파종시기를 앞당긴다면 입모중 파종보다 더 많은 생체량 생산이 가능할 것으로 판 단된다.

헤어리베치를 토양에 환원하고 벼를 재배한 후 벼의 분 얼기 (이앙 후 28일)와 출수기 (이앙 후 83일)에 초장, 경수 및 토양의 암모니아태 질소를 분석하였다 (Table 3).

초장과 경수는 이앙 후 28 일과 이앙 후 83 일 모두 유의적 차이를 나타내지 않았다. 암모니아태 질소는 이앙 후 28 일 에 부분경운 파종에서 벼 입모중 파종에 비하여 더 높은 경 향을 나타내었는데, 이는 볏짚을 제거하는 부분경운 파종과 달리 벼 입모중 파종에서 볏짚이 그대로 토양에 환원되었기 때문으로 사료되었다. 이앙 후 83일에는 부분경운파종 처리 가 벼 입모중 파종 처리보다 암모니아태 질소의 함량이 다

Table 1. Characteristics of growth (11.11) of hairy vetch before overwintering in paddy field.

\begin{tabular}{cccc}
\hline \hline Seeding method & Cultivar & No. of establishment & \multicolumn{2}{c}{ Plant height } \\
\hline \multirow{2}{*}{ PTS $^{\dagger}$} & & no. m ${ }^{-2}$ & $\mathrm{~cm}$ \\
& Cheongpungbora & 177.3 & 5.4 \\
\cline { 2 - 4 } & Imported cultivar & 164.4 & 5.5 \\
\hline \multirow{2}{*}{ BBRH $^{*}$} & Cheongpungbora & 152.2 & 10.9 \\
\cline { 2 - 4 } & Imported cultivar & 166.7 & 10.7 \\
\hline
\end{tabular}

${ }^{\dagger}$ PTS: partial tillage seeding, ${ }^{\ddagger}$ BBRH: broadcasting before rice harvesting

Table 2. Biomass and nitrogen production of hairy vetch by different seeding methods in paddy field.

\begin{tabular}{|c|c|c|c|c|}
\hline Seeding method & Cultivar & Fresh weight & Dry weight & $\mathrm{N}$ production \\
\hline \multirow{3}{*}{$\operatorname{PTS}^{\dagger}$} & & \multicolumn{3}{|c|}{ 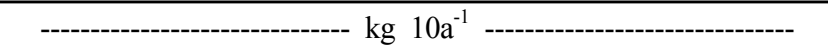 } \\
\hline & Cheongpungbora & $1,389.0 \mathrm{a}$ & $233.0 \mathrm{a}$ & $8.7 \mathrm{a}$ \\
\hline & Imported cultivar & $1,239.6 \mathrm{a}$ & $186.7 \mathrm{~b}$ & $5.8 \mathrm{~b}$ \\
\hline \multirow{2}{*}{$\mathrm{BBRH}^{\ddagger}$} & Cheongpungbora & $1,391.4 \mathrm{a}$ & 248.1a & $8.8 \mathrm{a}$ \\
\hline & Imported cultivar & $884.3 b$ & $181.4 \mathrm{~b}$ & $6.3 \mathrm{~b}$ \\
\hline
\end{tabular}

${ }^{\dagger}$ PTS: partial tillage seeding, ${ }^{\ddagger} \mathrm{BBRH}$ : broadcasting before rice harvesting 
Table 3. Height, tiller number leaf color of rice according to days after rice transplanting (DAT) in paddy field.

\begin{tabular}{cccccccc}
\hline \hline \multirow{2}{*}{$\begin{array}{c}\text { Seeding } \\
\text { method }\end{array}$} & \multirow{2}{*}{ Cultivar } & \multicolumn{3}{c}{ 28 DAT } & \multicolumn{3}{c}{83 DAT } \\
\cline { 3 - 9 } & & Plant height & Tiller & H4-N & Plant height & Tiller & H4-N \\
\hline \multirow{3}{*}{ PTS $^{\dagger}$} & Cheongpungbora & 30.9 & 26.1 & 34.6 & 98.8 & 26.3 & 3.03 \\
\cline { 2 - 9 } & Imported cultivar & 29.5 & 24.6 & 31.6 & 99.4 & 26.4 & 2.94 \\
\hline \multirow{2}{*}{ BBRH $^{\ddagger}$} & Cheongpungbora & 31.0 & 28.0 & 25.0 & 103.4 & 25.6 & 4.40 \\
\cline { 2 - 9 } & Imported cultivar & 30.4 & 25.6 & 21.9 & 98.5 & 23.4 & 4.30 \\
\hline
\end{tabular}

${ }^{\dagger}$ PTS: partial tillage seeding, ${ }^{\ddagger}$ BBRH: broadcasting before rice harvesting

Table 4. Effects of incorporation of hairy vetch on rice yield and its components in response to different seeding methods.

\begin{tabular}{|c|c|c|c|c|c|c|}
\hline Seeding method & Cultivar & Panicle & Spikelets & Ripened grain & 1,000 grain weight & Rice yield \\
\hline \multirow{3}{*}{$\operatorname{PTS}^{\dagger}$} & & no. hill ${ }^{-1}$ & no. panicle $^{-1}$ & $\%$ & Brown rice, g & $\mathrm{kg} 10 \mathrm{a}^{-1}$ \\
\hline & Cheongpung bora & 23.7 & 75.1 & 83.9 & 21.0 & $467 \mathrm{a}$ \\
\hline & Imported cultivar & 24.2 & 68.6 & 79.0 & 21.1 & $456 \mathrm{a}$ \\
\hline \multirow{2}{*}{$\mathrm{BBRH}^{\ddagger}$} & Cheongpungbora & 24.7 & 78.0 & 84.2 & 21.5 & $467 \mathrm{a}$ \\
\hline & Imported cultivar & 23.3 & 74.5 & 86.0 & 21.5 & $455 \mathrm{a}$ \\
\hline
\end{tabular}

${ }^{\dagger}$ PTS: partial tillage seeding, ${ }^{\ddagger}$ BBRH: broadcasting before rice harvesting

소 낮은 수치를 나타냈으나 처리간 유의한 차이는 없었다. 헤어리베치를 토양에 환원하고 벼를 재배한 후 조사한 벼의 수량 및 수량구성요소를 Table 4 에 나타내었다.

벼 수량은 헤어리베치의 파종방법 간 차이를 나타내지 않았다. 헤어리베치의 부분경운 파종이 벼 입모중 파종보다 21 일 늦었으나 헤어리베치의 생체량에 차이가 없었고 (Table 1, Table 2), 후작 벼의 수량도 부분경운 파종과 벼 입모중 파종 처리에서 유의한 차이를 나타내지 않았다 (Table 3, Table 4). 이는 헤어리베치의 부분경운 파종에서 벼 입모중 파종보다 안정적인 입모수 확보가 가능하여 헤어리베치 생 육기간의 부족을 극복하고 대등한 녹비 생체량와 벼 수량을 얻을 수 있었던 것으로 생각된다. 따라서 동계 녹비작물의 부분경운 파종방법은 녹비작물 생육기간 중 안정적인 입모 수 확보와 배수성 개선이 가능하여 벼 입모중 파종에 비해 재배 안전성을 높일 수 있을 것으로 판단되었다.

\section{References}

Azam, F. 1990. Comparative effects of organic and inorganic nitrogen sources applied to a flooded soil on rice yield and availability of N. Plant Soils. 125:255-262.

Clark, A. 2007. Managing cover crops profitably (third edition). Sustainable agriculture network. MD, USA.

FACT (Foundation of Agri. Tech. Commercialization \& Transfer). 2011. The Guidebook of Agro-green Technologies. Sammi. Suwon. pp. 193-213.
Hartwig, N.L. and H.U. Ammon. 2002. Cover crop and living mulches. Weed Sci. 50:688-699.

Jeon, W.T., M.T. Kim, K.Y. Seong, J.K. Lee, I.S. Oh, and S.T. Park. 2008. Changes of soil properties and temperature by green manure under rice-based cropping system. Korean J Crop Sci 53:413-416.

Jeon, W.T., K.Y. Seong, M.T. Kim, I.S. Oh, B.S. Choi, and U.G. Kang. 2011a. Effect of Biomass and N Production by Cultivation Methods of Leguminous and Gramineae Green Manures on Rice Growth in Central Regions of Korea. Korean J. Soil Sci. Fert. 44(5):853-858.

Jeon, W.T., B.S. Choi, Abd EL-Azeem SAM, and Y.S. Ok. 2011b. Effect of different seeding methods on green manure biomass, soil properties and rice yield in rice based cropping systems. African J Biotechnol 10:2024-2031.

Kim, C.G., J.H. Seo, H.S. Cho, S.H. Cho, and S.J. Kim. 2002. Effect of hairy vetch as green manure on rice cultivation. Korean J. Soil Sci. 35(3):169-174.

Lee, H.J. 1983, The history of Korea agricultural technology. V. Production technology of forage and green manure crops. Jungminsa. Suwon Korea pp. 433-459.

MAF (Ministry of Agriculture and Forestry, Republic of Korea). 2012. MAF, Korea.

NIAST (National institute of Agricultural Science and Technology). 2000. Methods of analysis of soil and plant, NIAST, Suwon, Korea.

RDA. 2003. Standard methods for agricultural experiments. Rural Development Administration, Suwon, Korea. 